\title{
Technology of eliminating outburst by downward drilling in high ground pressure and serious outburst area
}

\author{
Enbing $\mathrm{Yi}^{1,2, *}$ \\ ${ }^{1}$ State Key Laboratory of The Gas Disaster Detecting, Preventing and Emergency Controlling, Chongqing 400037, China \\ ${ }^{2}$ China Coal Technology and Engineering Group Chongqing Research Institute, Chongqing 400037, China
}

\begin{abstract}
The high-drainage roadway construction face of the working face is used to pre-drill the borehole under the tunneling face, and the problem of poor water return in the hole is solved by grouting the surrounding rock cracks in the deep and shallow holes of the drill floor. The "two plugs and one note" sealing method was adopted to ensure that the sealing holes were tight and airtight; the water pipes were blown all the way in the hole, and the single hole, grouping and timed water blowing work targets were realized, and the drilling effect of the downhole drilling was improved. A set of efficient and rapid down-drilling and holedissipation management mode has been formed, which has achieved the goal of high-efficiency outburst of coal seams and technical and economic integration in areas with high ground pressure and serious safety and economic benefits.
\end{abstract}

\section{Introduction}

With the increase of mining depth and mining intensity, coal seam gas content and in-situ stress increase, and the degree of outburst risk is more serious ${ }^{[1-2]}$. With the characteristics of high disaster intensity, difficult prevention and control, and serious disaster loss, the requirements for coal and gas outburst control are higher ${ }^{[3-}$ 4]. In order to effectively prevent and control coal and gas outburst accidents, according to "Regulations on prevention and control of coal and gas outburst" and production experience, gas drainage is the fundamental measure to solve coal and gas outburst and other power disasters, which plays an important role in reducing gas pressure and eliminating coal and gas outburst and other power disasters. The gas drainage technology of through seam drilling is to advance the coal seam to construct the rock roadway in a certain distance from the top (bottom) plate of the coal seam, and through the roadway to construct the through seam drainage drilling in the coal body around the coal seam roadway. After a certain period of pre drainage, the risk of coal and gas outburst in front of the heading face is reduced or even eliminated, The safety and outburst prevention pattern of rock roadway shield coal roadway driving is formed.

\section{Project overview}

1232 (1) working face elevation is -803 -910 m, strike length is $1600 \mathrm{~m}$, inclined length is $115 \mathrm{~m}$, average thickness of 11-2 Coal seam is $2.5 \mathrm{~m}$, measured original gas content is $7.2 \mathrm{~m}^{3} / \mathrm{t}$, gas pressure is $1.20 \mathrm{MPa}$. The north of the working face is close to the $\mathrm{F} 84$ reverse fault $(\mathrm{H}=45$ $\mathrm{m})$, the nearest horizontal distance is $30 \mathrm{~m}$, and the SF34 reverse fault $(\mathrm{H}=10 \mathrm{~m})$ is developed in the working face. The whole working face is in the area of high ground pressure serious outburst, so it must be relieved before the excavation construction. Before the tunnelling of 1232 (1) track chute, a high pumping roadway is designed, which is $35 \mathrm{~m}$ away from the track chute and $25-30 \mathrm{~m}$ away from the 11-2 Coal seam. In the high pumping roadway, the downward strip pre pumping borehole is constructed to relieve pressure and eliminate outburst.

\section{Technology of pre pumping and outburst elimination in downward drilling}

\subsection{Requirements for jet grouting in drilling field}

In 1232 (1) high pumping roadway, a drilling field is arranged every $40 \mathrm{~m}$ to clean the floating gangue to the bottom. The cement floor with a thickness of not less than $100 \mathrm{~mm}$ is constructed. After the cement is solidified, eight $2 \mathrm{~m}$ shallow holes are constructed in the bottom plate of the drilling field, and seven 8 holes are constructed by drilling machine after grouting The grouting pipe (the hole is $2 \mathrm{~m}$ down) is used to seal the cracks of surrounding rock by grouting, so as to ensure that the surrounding rock around the drilling site is tight without air leakage. The grouting pressure is not less than $4 \mathrm{MPa}$, and the grouting is repeated under pressure. The layout of grouting holes is shown in Figure 1. 


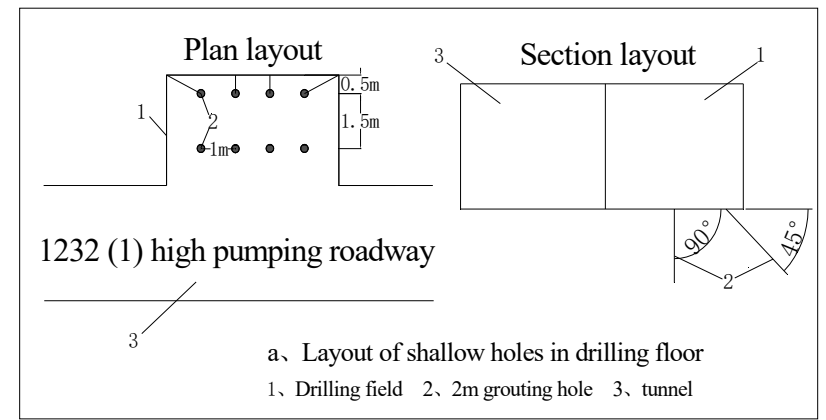

(a) layout of shallow grouting holes in drilling field

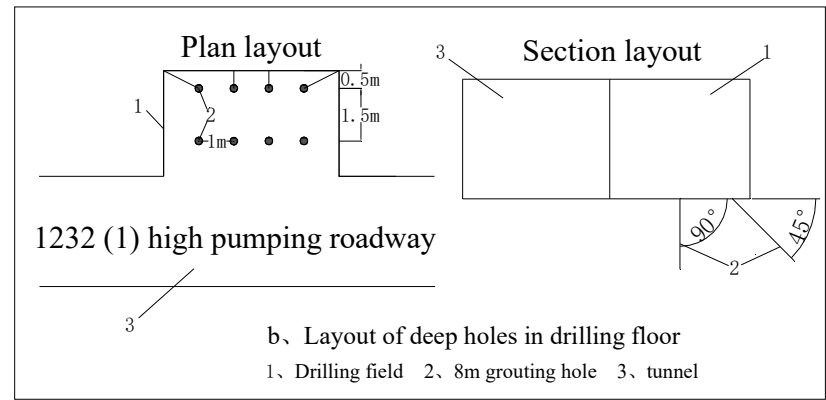

(b) layout of deep grouting holes in drilling field

Fig. 1. layout of deep and shallow grouting holes in drilling field

\subsection{Hydraulic punching for increasing permeability}

In order to improve the effect of drilling drainage, the hydraulic permeability enhancement construction was carried out for the cross layer drilling. The drilling was in place, the drill bit was retreated to the coal seam section, and the coal seam section was repeatedly washed with underground $4 \mathrm{MPa}$ static pressure water until the water returned to the hole.

\subsection{Drilling and sealing technology}

Due to the difficulty of slag removal in downward hole, the coal hole section is blocked because the drilling cuttings in the hole can not be effectively discharged. During the drilling construction, it is required to go through the 11-2 Coal Seam and then go down for $10 \mathrm{~m}$ to deposit the drilling cuttings and water in the hole, so as to ensure that the perforated pipe can go down to the coal stop.

\subsubsection{Running casing in the whole process}

In order to prevent collapse caused by surrounding rock deformation in the borehole, the whole process pipe protection technology is adopted. The 1-inch PVC pipe is placed in the hole to the coal stop. After the 1-inch PVC pipe is placed in place, the 2-inch PVC solid pipe is placed outside the 1-inch PVC pipe. The length of the 2 -inch solid pipe is not less than 20 meters. The outer opening of the 2 -inch pipe is connected with the iron pipe, and the later stubble extraction is carried out.

\subsection{2 "Two plugging and one injection" hole sealing grouting}

When the 2-inch PVC hole protecting pipe is put down, a bag is tied at the top, put into the hole, and inject Jiumi sodium to block the inner section. The next grouting pipe in the hole is to the bottom, and the next $2 \mathrm{~m}$ slurry return pipe at the orifice, and then a bag is used to block and fix the outer opening. Grouting through the grouting pipe, close the ball valve of the grouting pipe after returning the slurry, conduct the grouting under pressure for not less than 10 minutes, conduct the second grouting after 1 hour, open the grouting pipe, close the ball valve of the grouting pipe orifice after returning the slurry, and end the grouting. The schematic diagram of hole sealing grouting is shown in Figure 2.

\subsection{3 downdraft drainpipe}

In order to solve the problem of downward hole water blowing, through continuous practice and innovation, the goal of single hole blowing, group blowing and timing blowing was realized, and the problem of downward hole water blowing was completely solved. Through the four branch pipe connecting device reserved in the bypass, a 4point water blowing hose is put into the hole to the bottom of the hole to realize single hole water blowing. Each group of boreholes is connected to an air bag, and a gate valve is installed on the high-pressure rubber hose between the air bag and the pressure air pipe to realize group water blowing through the gate valve. The timing electronic valve is installed between the main pressure air pipeline and the partial pressure air pipeline to set the water blowing cycle and realize the timing water blowing function. The schematic diagram of water blowing pipeline is shown in Figure 3. 


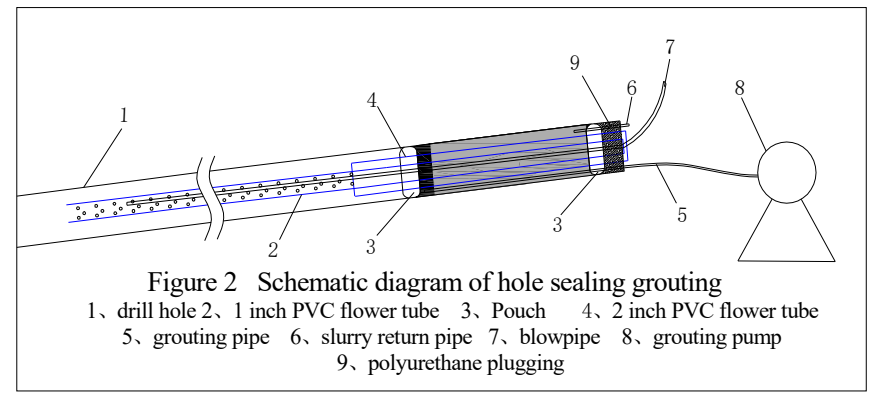

Fig. 2. Schematic diagram of hole sealing grouting

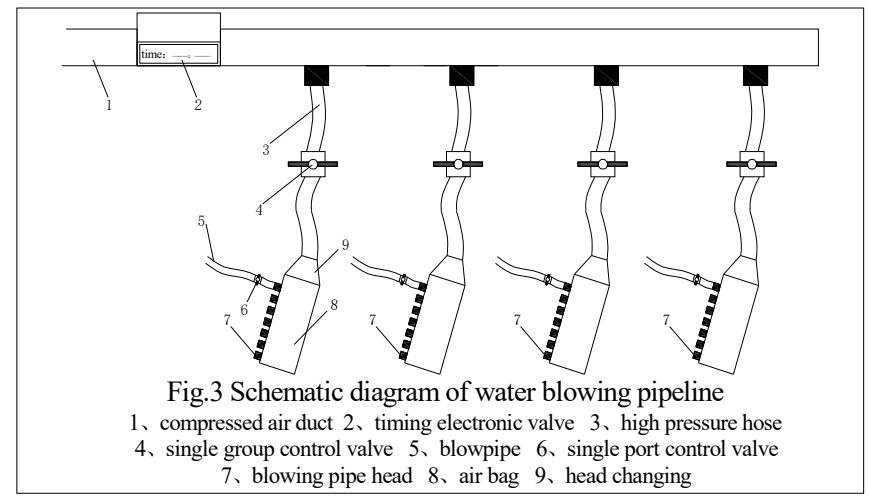

Fig.3. Schematic diagram of water blowing pipeline for downward through layer drilling

\section{Extraction effect of downward drilling through strata}

The 1232 (1) track strip pre pumping through layer drilling was carried out in 1232 (1) high pumping roadway. Due to the first use of downward drilling construction technology, the grouting reinforcement and plugging of surrounding rock cracks in the floor of the drilling field were not carried out before the first unit drilling construction, and the drainage problem of the downward hole was not considered, resulting in poor pumping effect of the unit. During the construction of the second unit drilling, the previous lessons were learned, and the technical improvement was carried out The results show that the effect of extraction is significantly improved by pre grouting of floor cracks and downdraft pipe. The comparison of pumping effect is shown in Figure 4 and Figure 5.

1232 (1) the concentration of the first unit is $10 \% \sim 20 \%$, the second unit is $45 \% \sim 50 \%$, the first unit is $1.0 \sim 1.3$ $\mathrm{m}^{3} / \mathrm{min}$, the second unit is $2.4 \sim 2.8 \mathrm{~m}^{3} / \mathrm{min}$. Through the above comparative analysis, after taking the measures of floor deep, shallow hole grouting, hydraulic punching, strengthening downward hole drainage and so on, the unit pumping concentration is high, the purity is large, and the pumping effect is very stable.

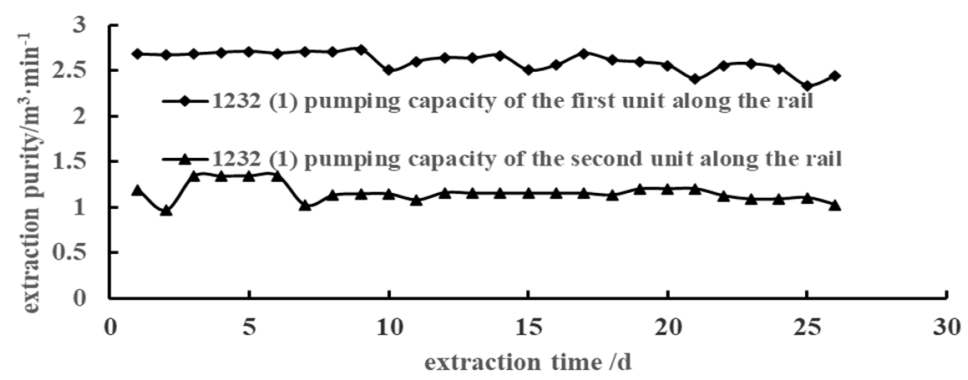

Fig.4. 1232 (1) comparison of pumping concentration in the first and second units of rail alignment

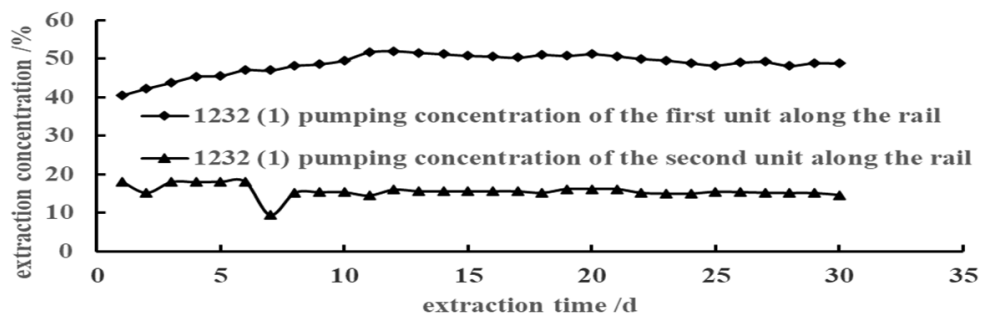

Fig.5. 1232 (1) comparison of pumping pure quantity of the first and second units along the rail 


\section{Conclusion}

(1) The effect of pre pumping is remarkable. Through grouting the floor of 1232 (1) high pumping Roadway Drilling Field to seal the cracks of surrounding rock, drilling hydraulic flushing, water blowing of down drainage device, tight sealing and other measures, the pumping concentration of down crossing drilling unit is greatly increased from $15 \% \sim 50 \%$.

(2) To achieve the purpose of rapid outburst elimination, the single hole extraction concentration of the second unit of 1232 (1) high pumping roadway is $50 \% \sim 80 \%$, and the attenuation is slow. The extraction concentration of strip pre pumping unit reaches $45 \% \sim 50 \%$, and the net flow rate is $2.60 \mathrm{~m}^{3} / \mathrm{min}$, which greatly improves the outburst elimination efficiency.

(3) Pre pumping and outburst elimination to realize safe footage of coal roadway. The construction of 1232 (1) track is close to the $\mathrm{F} 84$ reverse fault $(\mathrm{H}=45 \mathrm{~m})$ in the north. Affected by the closed fault, the gas in the working face is large and the ground pressure behavior is obvious. It is extremely difficult to prevent coal and gas outburst in coal roadway excavation. By strengthening the downward drilling strip pre drainage and on-site fine management and control, the real coal heading face is constructed safely and smoothly, and the return air gas in the working face is maintained at $0.2 \% \sim 0.3 \%$ The goal of tunneling in high gas and strong outburst coal seam in low gas state is to achieve the goal.

(4) Accumulate the construction experience of downward pre pumping and outburst elimination drilling. In the construction of downward cross layer strip pre pumping drilling, the surrounding rock of the floor is grouted and sealed to ensure that the orifice section is well formed and the return slag is normal, and the construction progress of 3 holes in each round shift is realized. At the same time, it is necessary to strengthen the management of water blowing (drainage) to prevent the water in the hole from blocking the borehole and affecting the gas drainage.

(5) Using a roadway construction downward hole pre drainage shield coal roadway driving, construction upward hole through the layer drainage pressure layer gas, at the same time, in the working face mining, as a high drainage roadway drainage working face goaf and adjacent layer pressure relief gas, realize a multi-purpose, technical and economic effect is remarkable.

\section{Reference}

1. Liu, Y.,He A.,Wei, J.P.,et al. (2016) Plugging factor and new plugging method to hydraulic relieving stress Journal of China Coal Society,41:1963-1967.

2. Sun,W.Z. (2017) High efficient gas drainage principle and application of low permeable seam with $\mathrm{CO}_{2}$ prefracturing and permeability improvement.Coal Science and Technology,45:100-105.

3. Meng,J. (2013) Experimental Study of Long-hole Pre-splitting Blast Through Strate in Floor Gateway to Increase Permeability of the DINGJI Coal
Mine.AnHui University of Science and Technology.

4. Wang,T.,Wang,Z.H.,Liu,H.B.,et al. (2014) Discussion about the mechanism of gas disaster induced by coal bump.Journal of China Coal Society,39:371-376. 